\title{
Ethical Issues in Pediatric Neurosurgery Practice: The Neurosurgical Point of View
}

\author{
Dimitrios Panagopoulos* \\ Department of Pediatric, Sophia
}

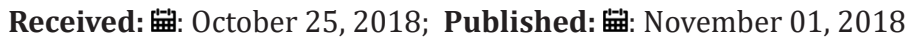

*Corresponding author: Dimitrios Panagopoulos, Consultant Neurosurgeon at Neurosurgical Department of Pediatric, Sophia, Greece

\section{Opinion}

Although there is no one definition of the term ethics, in general, it encompasses the various approaches to understanding and examining moral behavior. The study of ethics can be broadly classified into two areas: Normative and non-normative ethics. Normative ethics seems to answer the question, 'What ought I do' for a given moral dilemma, whereas non-normative ethics simply describes how people reason and act in moral situations, without commenting on the inherent 'rightness' of their actions. The application of these principles to health care is a relatively young field. It seeks to define, analyze, and guide decision-making in medicine, as it relates to the moral issues that confront both health care providers and patients. The last four decades have seen tremendous growth in the field of biomedical ethics- there is little doubt that the proliferation of ethics teaching has resulted in a heightened awareness of ethical issues and dilemmas in medicine.

There is perhaps no other specialty in medicine that is confronted with ethical quandaries on a daily basis more than pediatric neurological surgery. From severe congenital nervous system malformations, to premature new borns, to qualityof-life and end-of-life issues, pediatric neurosurgeons make medical decisions with profound ethical, spiritual, and religious consequences on an ongoing basis. The root of bioethics date back to the fifth century BC when Hippocrates codified his musings on how a physician should act into the Oath of Hippocrates. The modern resurgence of bioethics occurred in the late 1940s. The Doctors' Trials in Nuremberg from 1946 to 1947 resulted in the formulation of the Nuremberg Code, outlining a list of requirements for the ethical conduct of human-subjects research. The Nuremberg Code has been largely replaced by the World Medical Federation's Declaration of Helsinki, last revised in 2002. In both the teaching of bioethics and the application of bioethics to clinical medicine, many ethicists use a variety of ethical frameworks-specific lenses through which a particular ethical issue can be seen- to better outline the crux of the ethical matter at hand.

\section{Principilism}

Principilism refers to the 'four pillars' of modern bioethics: autonomy, nonmaleficence, beneficence and justice.

\section{Respect for Autonomy}

The concept of autonomy has superseded the tradition of beneficent paternalism, where patients essentially trusted that their physicians would make appropriate decisions, medically and ethically, on their behalf. Autonomy is the core of the concept of informed consent, in that a person cannot make a truly autonomous decision without fully understanding the risks, benefits and alternatives to the proposed therapy. Pediatric neurosurgeons deal with the difficulties associated with the concept of autonomy in that many of our patients, by virtue of their age, disease, developmental status or statutory restrictions do not have the ability to make decisions on their own, and as such, we must rely on substitute decision makers, in most cases their parents. A common criticism of Western bioethics is the perceived overemphasis on the principle of autonomy.

\section{Nonmaleficence}

Primum non nocere or 'first do not harm', based on Hippocratic principles, effectively summarizes the principle of nonmaleficence. Virtually any intervention in medicine in general, and perhaps more so in neurosurgery in particular, carries with it the potential to do harm; therefore, it may be better to express the principle of nonmaleficence in terms of undue risk of harm or intent to harm. The principle of nonmaleficence and the importance of intent are often cited when contrasting withholding versus withdrawing treatment and killing versus letting die.

\section{Beneficence}

Beneficence refers to the act of doing or producing good or performing acts of kindness and charity. In the context of medical 
intervention, the intent or hoped-for outcome in an intervention must have a reasonable chance of producing some benefit to the patient, or conversely, in preventing harm from coming to him from the disease.

\section{Justice}

Justice is described as what is fair or deserved, or what one is entitled to. Distributive justice 'refers to fair, equitable, and appropriate distribution determined by justified norms that structure the terms of social cooperation'. The allocation and rationing of health-care resources at all levels and priority setting in health-care institutions are issues in which the principle of justice plays a role.

\section{Ethical Issues}

One of the more controversial topics in bioethics has been the discussion over medical futility and stemming from this, quality of life-specifically, is there a threshold quality of life below which life cannot be considered worth living. Futility has been described as having four separate types: physiologic futility (the intervention does not have its intended physiologic effect); imminent demise futility (the patient will die before discharge regardless of the intervention); lethal condition futility (the patient will die, no matter the treatment); and qualitative futility (treatment is futile because quality of life is so poor).

In pediatric neurosurgery, decisions regarding futility can often place physicians in conflict with parents or guardians, either by parents insisting on treatment that a surgeon feels is futile, or by refusing treatment that the surgeon feels is indicated and, in the child's, best interests. Appeals to ethical principles do not necessarily resolve the conflict easily, as ethical principles can often conflict.

\section{Informed Consent and Assent}

Parents and guardians have traditionally been considered substitute decision makers for their children for making medical decisions. The evolution of the process of obtaining informed consent from a patient has paralleled the development of the ethical concept of autonomy. Young patients may not have the capacity to fully understand the consequences of medical decision-making and are not considered to be fully autonomous individuals. Given this, we ask their parents or guardians to act as surrogate decision makers.

When parents, as proxy decision-makers for their children, act in a way that seems counter to the best interests of their children, physicians are not obligated to follow parental direction. Commonly encountered examples occur when parents decline life-saving treatment for their children on religious grounds. Clearly surgeons should do all they can to make decisions in concert with families but are under due obligation, legally and morally, to provide or withhold treatment when they feel it to be in the best interests of young patients unable to provide consent themselves.
Although most children below the statutory age of consent or majority do not have the legal authority to provide informed consent, it has become increasingly common to include children, especially adolescents, in the decision-make process. This has become popularly known as obtaining 'assent' to treatment. Obtaining assent from a child includes informing the child, in an age-appropriate manner, of the nature of the illness, explaining the likely course of action including testing and therapy, and assessing the child's understanding of the situation and willingness to proceed (or refuse) the proposed treatment.

\section{End-of-Life Issues}

According to most relevant consensus guidelines regarding end-of-life care, there is 'no ethical distinction between withholding or withdrawal of life-sustaining treatment' and physicians should 'aggressively treat pain with analgesic drugs and, when needed, with heavy sedation, even if these treatments hasten death'. Pediatric neurosurgeons should play a leading role in ensuring that our patients with terminal illnesses die with the dignity and comfort they deserve.

\section{Research and Children}

Children are considered a potentially vulnerable population in research ethics. There are several vulnerabilities in pediatric research subjects that should be considered:

a) They commonly lack the capacity to make mature decisions;

b) They are subject to the authority of others;

c) They, and their parents, may be deferential in ways they can mask dissent;

d) Their rights and interests may be socially undervalued;

e) They may have acute medical conditions requiring immediate attention that make informed consent impractical;

f) They may have serious medical conditions that cannot be effectively treated;

g) They may lack access to social benefits, such as health care.

Much work continues and needs to be done regarding the ethics of clinical research in the pediatric population. In the end, a balance between the need for important clinical research in pediatric neurosurgery and the protection of potentially vulnerable research subjects must be found.

When facing an ethical problem that requires rapid resolution, the first step is to make sure that one is in possession of all the relevant facts about the natural history of the patient's medical condition, the alternative forms of treatment, including nonintervention, the recently reported outcome figures, and the complication rates of each method of treatment. Next, one must put oneself in the place of the patient. One assumes the role of sole 
advocate for the child and considers what one would want to have done to oneself if one were the patient, not what the parents or the family might want done for the child. Finally, there must be no intention to do harm• it is the intention that counts. No two ethical problems are the same in pediatric neurosurgery, and each one must be reviewed on its own merits, considering the many issues as they apply to a particular child.

\section{ISSN: 2574-1241}

DOI: $10.26717 / B J S T R .2018 .10 .001993$

Dimitrios Panagopoulos. Biomed J Sci \& Tech Res

CC (i) This work is licensed under Creative

Submission Link: https://biomedres.us/submit-manuscript.php

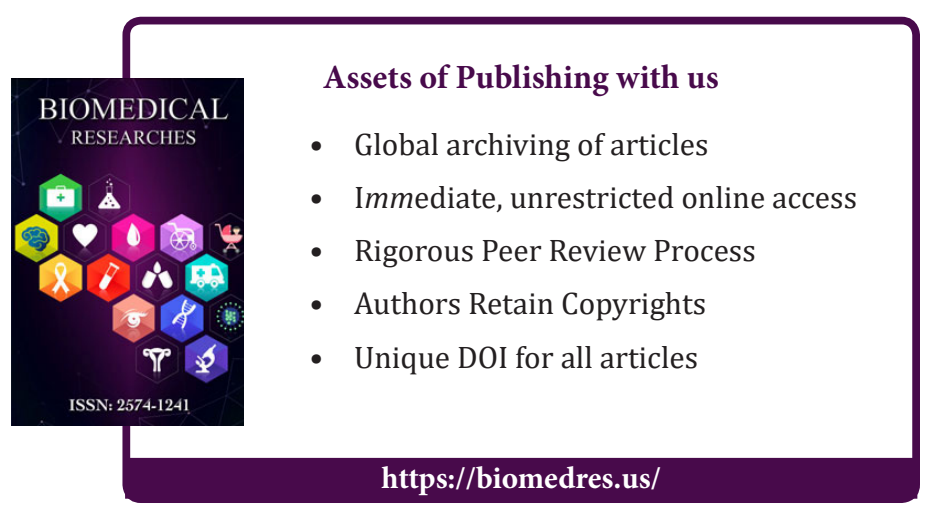

